\title{
Genetic architecture of open-pollinated varieties of pearl millet for grain iron and zinc densities
}

\author{
Anand Kanatti ${ }^{1}$, Kedar Nath Rai*, Kommineni Radhika ${ }^{1}$ and Mahalingam Govindaraj \\ International Crops Research Institute for the Semi-Arid Tropics (ICRISAT), Patancheru, 502 324, Telangana; \\ ${ }^{1}$ Professor Jayashankar Telangana State Agriculture University (PJTSAU), Rajendranagar, 500 030, Telangana
}

(Received: November 2015; Revised: June 2016; Accepted: June 2016)

\begin{abstract}
Genetic architecture of two commercial open-pollinated varieties of pearl millet (ICTP 8203 and ICMV 221) for grain iron and zinc densities was studied using 160 full-sib progenies each that were developed following North Carolina Design -1 and evaluated for two seasons. Results showed predominantly additive genetic variance and nonsignificant additive gene effect $\times$ environment interaction variance compared to large and significant dominance $x$ environment interaction variance for both micronutrients in both populations. This translated into high narrow-sense heritability for Fe (65\%) and Zn (86\%) in ICTP 8203, and moderate heritability of $45 \%$ for both micronutrients in ICMV 221. In comparison, 1000-seed weight, generally assumed to be highly heritable, was predominantly under dominance gene control and had large dominance $\times$ environment interaction, giving the narrow-sense heritability estimates of $31 \%$ in ICTP 8203 and $13 \%$ in ICMV 221. These results, and highly significant and positive correlation observed between $\mathrm{Fe}$ and $\mathrm{Zn}$ densities, and non-significant correlations of these micronutrients with grain weight suggest that simultaneous selection for $\mathrm{Fe}$ and $\mathrm{Zn}$ densities in these populations can be effectively made without compromising the grain size.
\end{abstract}

Key words: Pearl millet, open pollinated variety, grain iron and zinc density, genetic variance

\section{Introduction}

Pearl millet (Pennisetum glaucum (L.) R. Br.) is a highly cross-pollinated crop with more than $85 \%$ outcrossing (Burton 1974). This breeding system makes openpollinated varieties (OPVs) and hybrids as the two broad cultivar types. Hybrids account for more than $85 \%$ of the pearl millet area (and improved OPVs the remaining 15\%) under improved cultivars in India, but OPVs are almost exclusively cultivated in the African countries. Thus, while the major thrust is on OPV development in African countries, hybrid development is the major research thrust in India, with OPV development as the distant second priority. OPVs of pearl millet are highly heterogeneous populations, with significant variability for most of the quantitative traits. This provides opportunities for their further genetic improvement by exploiting intra-population variability. An earlier pearl millet study identified several OPVs and composites with high levels of $\mathrm{Fe}$ and $\mathrm{Zn}$ densities (Velu et al. 2008). Also, significant intra-population variability for these micronutrients has been reported in pearl millet populations (Velu 2006). An understanding of the nature of genetic variability will have direct bearing on devising effective breeding strategies to further improve these populations for high $\mathrm{Fe}$ and $\mathrm{Zn}$ densities, and derive inbred lines with higher levels of both micronutrients for use as hybrid parents. However, there is no literature on the nature of intrapopulation variability for $\mathrm{Fe}$ and $\mathrm{Zn}$ densities in pearl millet. Thus, the objective of this study was to determine the nature and magnitude of genetic variability for $\mathrm{Fe}$ and $\mathrm{Zn}$ densities in two commercial OPVs of pearl millet.

\section{Materials and methods}

Two OPVs (ICTP 8203 and ICMV 221), identified in an earlier study for high levels of $\mathrm{Fe}$ and $\mathrm{Zn}$ densities (Rai et al. 2016), were used in this study. ICTP 8203 had been developed at ICRISAT by recombining $6 \mathrm{~S}_{2}$ progenies derived from a landrace from northern Togo, and it had been released in 1988 for cultivation in Peninsular India (Rai et al. 1990). ICMV 221 had been

${ }^{*}$ Corresponding author's e-mail: kedarrai64@gmail.com

Published by the Indian Society of Genetics \& Plant Breeding, F2, First Floor, NASC Complex, PB\#11312, IARI, New Delhi 110012

Online management by indianjournals.com 
developed at ICRISAT by recombining $241 \mathrm{~S}_{1}$ progenies derived from Bold-Seeded Early Composite, and released in 1993 for cultivation at the All India level (Witcombe et al. 1997). Full-sib progenies from both populations were produced following North Carolina mating design-1 (NCD-1) (Comstock and Robinson 1952; Robinson et al. 1955). In each population, 40 random plants, selected as male parents, were grouped into 10 sets of 4 plants. Each male plant from a set was crossed with 4 random and different female plants, ensuring that no female plant was crossed with more than one male plant. This produced 10 sets of full-sibs with 16 full-sibs each, and thus a total of 160 full-sibs for each population.

Progenies of each set were replicated thrice and evaluated at ICRISAT, Patancheru in replications-insets (within block RBD) experimental design proposed by Comstock and Robinson (1952), in which each set was evaluated in compact and uniform block for local control of experimental error. All the sets of both populations were accommodated in the same experimental field and evaluated for two seasons in 2012 rainy season and 2013 summer season. Each entry was planted in single row of $2 \mathrm{~m}$ length spaced at $0.60 \mathrm{~m}$ and $0.75 \mathrm{~m}$ between the rows in summer and rainy season, respectively. Overplanted plots were thinned after $15 \mathrm{~d}$ to a single plant spaced $0.15 \mathrm{~m}$ apart within each row. A basal dose of $100 \mathrm{~kg}$ diammonium phosphate (18\% $\mathrm{N}$ and $46 \% \mathrm{P})$ was applied at the time of field preparation and $100 \mathrm{~kg}$ of urea $(46 \% \mathrm{~N})$ was applied as top dressing within 2 to 4 $\mathrm{d}$ after thinning. Summer season trials were irrigated at 7-10 d interval to ensure no moisture stress during the crop season.

A recent study has shown that open-pollinated grain samples can be used for reliable estimation of grain $\mathrm{Fe}$ and $\mathrm{Zn}$ densities as there is neither xenia effect nor dust contamination effect on these micronutrients in pearl millet (Rai et al. 2015a). Openpollinated grain samples were collected and analyzed for grain Fe and Zn densities using Inductively Coupled Plasma Optical Emission Spectrometry (ICP-OES) at the Charles Renard Analytical Laboratory, ICRISAT, Patancheru, following the closed-tube method as described by Wheal et al. (2011). For each entry random samples of 200 grains were weighed and then multiplied by 5 to determine 1000-grain weight.

Data were analyzed using Statistical Analysis Systems (SAS) version 9.2 (SAS Institute 2009). ANOVA for individual environments and pooled over the two environments were performed using Generalized Linear Model procedures using a randomeffects model (Hallauer et al. 1988). Satterthwaite's approximation was used to obtain the appropriate degrees of freedom for the synthesized F-test (where direct $F$-test is not possible) i.e. F-test for males-insets was estimated by using the ratio (mean squares of males-in-sets + mean squares of females-in-malesin-sets $\times$ environments)/(mean squares of femalesin-males-in-sets + mean squares of males-in-sets $x$ environments); accordingly approximate degrees of freedoms were calculated for numerator and denominator factors (Satterthwaite 1941, 1946). Associations among the traits were determined by the Pearson correlation coefficient.

\section{Result and discussion}

About 2-fold differences among the full-sibs were observed for Fe density, varying from 44.0 to $78.3 \mathrm{mg}$ $\mathrm{kg}^{-1}$ in ICTP8203 and 38.3 to $73.6 \mathrm{mg} \mathrm{kg}^{-1}$ in ICMV221 (Table 1). Relatively smaller proportionate differences were observed for $\mathrm{Zn}$ density in both populations. There were highly significant differences $(P<0.01)$ among females-in-males-in-sets and among males-in-sets for both micronutrients in both populations (Table 2). While there were highly significant females-in-males-in-sets

Table 1. Mean and range for grain iron (Fe) and zinc (Zn) densities and 1000-grain weight (GW) in full-sib progenies of pearl millet, mean of two environments (2012 rainy and 2013 summer seasons), Patancheru

\begin{tabular}{llccc}
\hline Population & Trait & Mean & Range & SE \pm \\
\hline ICTP 8203 & Fe density $\left(\mathrm{mg} \mathrm{kg}^{-1}\right)$ & 57.9 & $44.0-78.3$ & 2.07 \\
& Zn density $\left(\mathrm{mg} \mathrm{kg}^{-1}\right)$ & 42.8 & $33.0-51.0$ & 1.80 \\
& 1000-grain weight $(\mathrm{g})$ & 16.6 & $13.5-20.4$ & 0.47 \\
ICMV 221 & Fe density $\left(\mathrm{mg} \mathrm{kg}^{-1}\right)$ & 52.1 & $38.3-73.6$ & 2.17 \\
& Zn density $\left(\mathrm{mg} \mathrm{kg}^{-1}\right)$ & 39.4 & $31.3-48.8$ & 1.56 \\
& 1000-grain weight $(\mathrm{g})$ & 15.1 & $12.0-19.0$ & 0.52 \\
\hline
\end{tabular}


Table 2. Mean square for grain iron (Fe) and zinc (Zn) densities and 1000-grain weight (GW) in full-sib progenies of ICTP 8203 and ICMV 221, Patancheru

\begin{tabular}{|c|c|c|c|c|c|c|c|}
\hline \multirow[t]{3}{*}{ Source of variation } & \multirow[t]{3}{*}{ df } & \multicolumn{6}{|c|}{ Mean square } \\
\hline & & \multicolumn{3}{|c|}{ ICTP 8203} & \multicolumn{3}{|c|}{ ICMV 221} \\
\hline & & $\mathrm{Fe}$ & $\mathrm{Zn}$ & GW & $\mathrm{Fe}$ & $\mathrm{Zn}$ & GW \\
\hline Environment & 1 & $77^{*}$ & $82116^{* *}$ & $1025^{* *}$ & 3965 ** & 103082 ** & $575^{*}$ \\
\hline Replication in sets in environment & 40 & 179 ** & 111 * & 2 ** & 212 ** & 314 ** & 2 \\
\hline Sets & 9 & $683^{* *}$ & 143 & $17^{* *}$ & $663^{*}$ & 68 & $25^{*}$ \\
\hline Sets $\times$ environment & 9 & 120 ** & 176 ** & 3 * & 159 ** & 78 ** & 6 ** \\
\hline Males in sets & 30 & 409 ** & $173^{* *}$ & $18^{* *}$ & 346 ** & 140 ** & $17^{* *}$ \\
\hline Females in males in sets & 120 & 124 ** & $48^{* *}$ & 6 ** & $141^{* *}$ & $53^{* *}$ & $6^{* *}$ \\
\hline Males in sets $\times$ environment & 30 & 53 & 36 & 3 & 49 & 40 & 3 \\
\hline Females in males in sets $\times$ environment & 120 & $43^{* *}$ & $27^{* *}$ & $2 * *$ & 59 ** & 31 * & 2 * \\
\hline Error & 600 & 26 & 19 & 128 & 15 & 2 & \\
\hline
\end{tabular}

${ }^{* * *}$ - Significant at the $0.05,0.01$ probability levels, respectively.

$x$ environment interactions for $\mathrm{Fe}$ and $\mathrm{Zn}$ densities in both populations, males-in-sets $\times$ environment interactions were non-significant. The contribution of females-in-males-in-sets $\times$ environment interactions to variability relative to those due to females-in-malesin-sets was $35 \%$ for Fe density and $56 \%$ for $\mathrm{Zn}$ density in ICTP 8203. In ICMV 221, females-in-males-in-sets $x$ environment interactions were significant for both micronutrients, and the contribution of these interactions to variability relative to those due to the females-in-males-in-sets were $42 \%$ for $\mathrm{Fe}$ density and $58 \%$ for $\mathrm{Zn}$ density. This indicated that estimates of total genetic variances $\left(\sigma^{2}{ }_{G}\right)$ were confounded with $G$ $\times E$ interaction variances $\left(\sigma_{G \times E}^{2}\right)$, while additive genetic variance components were not significantly influenced by this interaction component for $\mathrm{Fe}$ and $\mathrm{Zn}$ densities in both populations.

Analysis of NCD-1 experiments partitions total genetic variance $\left(\sigma_{G}^{2}\right)$ into additive variance $\left(\sigma^{2}{ }_{A}\right)$ and dominance variance $\left(\sigma^{2}\right)$, assuming no epistatic effects (Robinson et al. 1955). It may not be a too unrealistic assumption since in $98 \%$ of the studies on genetic variability conducted on a well-researched cross-pollinated crop like maize, epistatic variance was found to be non-significant (Hallauer et al. 1988). The $\sigma^{2}{ }_{A}$ was more than five times that of $\sigma^{2}{ }_{D}$ for Fe density, and it accounted for total $\sigma^{2}{ }_{G}$ for Zn density in ICTP 8203 (Table 3). In case of ICMV 221, $\sigma^{2}{ }_{A}$ was about twice that of $\sigma^{2}$ for Fe density and five times higher for $\mathrm{Zn}$ density. The variances due to interaction of additive gene effects with the environment $\left(\sigma_{\mathrm{A} \times \mathrm{E}}{ }^{2}\right)$ were much smaller than those arising from interaction of dominance effects with the environment $\left(\sigma^{2}{ }_{D \times E}\right)$ for both micronutrients and in both populations. While $\sigma^{2}{ }_{D \times E}$ accounted for $87 \%$ and $72 \%$ of the total $\sigma^{2}{ }_{G \times E}$ for $\mathrm{Fe}$ and $\mathrm{Zn}$ densities, respectively, in ICTP 8203; it accounted for the total $\sigma^{2}{ }_{G \times E}$ for Fe density and $85 \%$ of the $\sigma^{2}{ }_{G \times E}$ for $Z n$ density in ICMV 221. The greater additive genetic variance and proportionately less genotype $\times$ environment interaction variance translated into higher narrow-sense heritability of $65 \%$ for $\mathrm{Fe}$ density and $86 \%$ for Zn density in ICTP 8203 . Moderate heritability of $45 \%$ for both micronutrients, resulting from smaller additive genetic variance and/or proportionately high genotype $\times$ environment interaction variance component, was observed in ICMV 221. Earlier studies in pearl millet (Velu et al. 2011; Govindaraj et al. 2013; Kanatti et al. 2014) have also reported these micronutrients to be largely under additive genetic control. The predominance of additive genetic variance and moderate to high heritability would make intra-population improvement, and openpollinated variety development highly effective, both for Fe and Zn densities. For instance, Dhanashakti, a higher-Fe version could be developed by exploiting intra-population variability from ICTP 8203, which had $9 \%$ higher Fe density and $11 \%$ higher grain yield than ICTP 8203 (Rai et al. 2014). The improved versions of such OPVs and composites with higher levels of $\mathrm{Fe}$ and $\mathrm{Zn}$ densities can then be used more effectively to breed parental lines of hybrids with higher levels of these micronutrients. Further, there were highly significant positive correlations between these two 
Table 3. Variance components and narrow-sense heritability for grain iron (Fe) and zinc (Zn) densities and 1000-grain weight (GW) in ICTP 8203 and ICMV 221, Patancheru

\begin{tabular}{|c|c|c|c|c|c|c|c|c|}
\hline Population & Trait & $\sigma_{A}^{2}$ & $\sigma_{D}^{2}$ & $\sigma_{G}^{2}$ & $\sigma^{2}{ }_{A \times E}$ & $\sigma_{\text {DXE }}^{2}$ & $\sigma_{\mathrm{GXE}}^{2}$ & $\mathrm{~h}_{n s}^{2}(\%)$ \\
\hline \multirow[t]{3}{*}{ ICTP 8203} & $\mathrm{Fe}\left(\mathrm{mg} \mathrm{kg}^{-1}\right)$ & 45.91 & 8.16 & 54.06 & 3.12 & 20.43 & 23.55 & 65 \\
\hline & $\mathrm{Zn}\left(\mathrm{mg} \mathrm{kg}^{-1}\right)$ & 19.31 & -5.16 & 14.15 & 2.85 & 7.26 & 10.11 & 86 \\
\hline & GW (g) & 1.79 & 2.36 & 4.15 & 0.51 & 2.09 & 2.61 & 31 \\
\hline \multirow[t]{3}{*}{ ICMV 221} & $\mathrm{Fe}\left(\mathrm{mg} \mathrm{kg}^{-1}\right)$ & 35.87 & 18.88 & 54.75 & -3.38 & 43.84 & 40.46 & 45 \\
\hline & $\mathrm{Zn}\left(\mathrm{mg} \mathrm{kg}^{-1}\right)$ & 12.82 & 2.4 & 15.21 & 3.23 & 18.06 & 21.29 & 45 \\
\hline & GW (g) & 0.60 & 2.74 & 3.34 & 0.72 & 1.16 & 1.88 & 13 \\
\hline
\end{tabular}

$=$ Dominance $\times$ environments variance; $h_{n s}^{2}=$ Narrow-sense heritability

micronutrients in ICTP $8203(r=0.69, p<0.01)$ and ICMV $221(r=0.63)$. Earlier studies in pearl millet have also reported highly significant and high positive correlations between these two micronutrients (Velu et al. 2008; Gupta et al. 2009; Rai et al. 2012, 2013, 2015b; Kanatti et al. 2014), indicating that simultaneous selection for both micronutrients are likely to be effective.

Seed weight is an important farmer-preferred and highly heritable trait. Thus, variance components and heritability for seed weight were also studied as a reference for $\mathrm{Fe}$ and $\mathrm{Zn}$ density estimates. In proportionate term, 1000-seed weight among the progenies varied as much as the $\mathrm{Zn}$ density, varying from $13.5 \mathrm{~g}$ to $20.4 \mathrm{~g}$ in ICTP 8203 and 12.0 to 19.0 in ICMV 221 (Table 1). In both OPVs, there were highly significant differences among the males-in-sets and among the females-in-males-in sets (Table 2); and estimates of $\sigma^{2}{ }_{D}$ were higher than $\sigma^{2}{ }_{A}$ (Table 3). Also, estimates of $\sigma^{2}{ }_{D x E}$ were higher than $\sigma_{A \times E}^{2}$; and $\sigma^{2}{ }_{G \times E}$ were higher than $\sigma^{2}{ }_{A}$ in both populations. This translated into lower narrow-sense heritability of $31 \%$ in ICTP 8203 and 13\% in ICMV 221. These results indicate that intra-population improvement for $\mathrm{Fe}$ and Zn density would be more effective than for 1000 -seed weight, at least in these two populations. There was no correlation between these two micronutrients on one hand and 1000-seed weight on the other $(r=<$ 0.16). Lack of association or positive association of $\mathrm{Fe}$ and $\mathrm{Zn}$ density with grain size has also been reported in earlier pearl millet studies (Gupta et al. 2009; Rai et al. 2012; Kanatti et al. 2014), indicating that genetic improvement for $\mathrm{Fe}$ and $\mathrm{Zn}$ density can be made without compromising the grain size.

\section{Authors' contribution}

Conceptualization of research (KNR, KR); Designing of the experiments (AK, KNR, KR); Contribution of experimental materials (KNR); Execution of field/lab experiments and data collection (AK); Analysis of data and interpretation (AK, KNR, KR, MG); Preparation of the manuscript (AK, KNR, KR, MG).

\section{Declaration}

The authors declare no conflict of interest.

\section{Acknowledgments}

This research is a part of a Ph.D. thesis of A Kanatti, submitted to Professor Jayashankar Telangana State Agricultural University, Hyderabad, Telangana, India. It was supported by HarvestPlus Challenge Program of the CGIAR and conducted under CGIAR Research Program on $\mathrm{A} 4 \mathrm{NH}$.

\section{References}

Burton G. W. 1974.Factor affecting pollen movement and natural crossing in pearl millet. Crop Sci., 14: 802805.

Comstock R. E. and Robinson H. F. 1952. Estimation of average dominance of genes. In Heterosis. lowa state College Press, Ames., 494-516.

Govindaraj M., Rai K. N., Shanmugasundaram P., Dwivedi S. L., Sahrawat K. L., Muthaiah A. R. and Rao A. S. 2013. Combining ability and heterosis for grain iron and zinc densities in pearl millet. Crop Sci., 53: 507517.

Gupta S. K., Velu G., Rai K. N. and Sumalini K. 2009.Associationof grain iron and zinc content with grain yield and othertraits in pearl millet (Pennisetum 
glaucum (L.) R. Br.). Crop Improv., 36: 4-7.

Hallauer A. R., Carena M. G. and Miranda Filho J. B. 1988. Quantitative genetics in maize breeding. $2^{\text {nd }}$ edn. lowa State Univ. Press, Ames, IA. 663.

Kanatti A., Rai K. N., Radhika K., Govindaraj M., Sahrawat K. L. and Rao A. S. 2014. Grain iron and zinc density in pearl millet: combining ability, heterosis and association with grain yield and grain size. Springer Plus, 3: 763.

Rai K. N., Anand Kumar K., Andrews D. J., Rao A. S., Raj A. G. B. and Witcombe J. R. 1990. Registration of ICTP 8203 pearl millet. Crop Sci., 30: 959.

Rai K. N., Govindaraj M. Pfeiffer W. H. and Rao A. S. 2015a. Seed set and xenia effects on grain iron and zinc density in pearl millet. Crop Sci., 55: 1-7.

Rai K. N., Govindaraj M. and Rao A. S. 2012. Genetic enhancement of grain iron and zinc content in pearl millet.Qual. Assur.Saf. Crop., 4: 119-125.

Rai K. N., Patil H. T., Yadav O. P., Govindaraj M., Khairwal I. S., Cherian B., Rajpurohit B. S., Rao A. S., Shivade H. and Kulkarni M. P. 2014. Variety Dhanashakti. Indian J. Genet., 74: 405-406.

Rai K. N., Velu G., Govindaraj M., Upadhyaya H. D., Rao A.S., Shivade H. and Reddy K. N. 2015b. Iniadi pearl millet germplasm as a valuable genetic resource for high grain iron and zinc densities. Plant Genet. Resour., 13: 75-82.

Rai K. N., Yadav O. P., Govindaraj M., Pfeiffer W. H., Yadav H. P., Rajpurohit B. S., Patil H. T., Kanatti A., Rathore A., Rao A. S. and Shivade H. 2016. Grain iron and zinc densities in released and commercial cultivars of pearl millet (Pennisetum glaucum). Indian J. agric. Sci., 86: 291-296.

Rai K. N., Yadav O. P., Rajpurohit B. S., Patil H. T., Govindaraj M., Khairwal I. S., Rao A. S., Shivade H.,
Pawar V. and Kulkarni M. P. 2013. Breeding pearl millet cultivars for high iron density with zinc density as an associated trait. J. SAT Agric. Res., 11: 1-7.

Robinson H. F., Comstock R. E. and Harvey P. H. 1955. Genetic variances in open-pollinated varieties of corn. Genetics, 40: 45-59.

Satterthwaite F. E. 1941. Synthesis of variance. Psychometrika, 6: 309-316.

Satterthwaite F. E. 1946. An approximate distribution of estimates of variance components. Biometrics Bull., 2: 110-114.

Statistical Analysis Systems Institute Inc. 2009. SAS/STAT ${ }^{\circledR}$ 9.2 User's Guide (2 ${ }^{\text {nd }}$ Edn.). Cary, NC: SAS Institute Inc.

Velu G., Rai K. N., Muralidharan V., Longvah, T. and Crossa J. 2011. Gene effects and heterosis for grain iron and zinc densityin pearl millet (Pennisetum glaucum (L.) R. Br). Euphytica, 180: 251-259.

Velu G. 2006. Genetic variability, stability and inheritance of grain iron and zinc content in pearl millet (Pennisetum glaucum (L.) R.Br.). Ph.D Thesis. Tamil Nadu Agricultural University, Coimbatore, India.

Velu G., Rai K. N. and Sahrawat K. L. 2008.Variability for grain iron and zinc content in a diverse range of pearl millet populations. Crop Improv., 35: 186-91.

Wheal M. S., Fowles T. O. and Palmer L. T. 2011. A costeffective acid digestion method using closed polypropylene tubes for inductively coupled plasma optical emission spectrometry (ICP-OES) analysis of plant essential elements. Anal. Methods, 3: 28542863.

Witcombe J. R., Rao M. N. V. R., Raj A. G. B. and Hash C. T. 1997. Registration of 'ICMV 88904' Pearl Millet. Crop Sci., 37: 1022-1023. 